\title{
Mycobacterium goodii related breast implant infection: First case and literature review
}

\author{
Aakriti Pandita $^{1 *}$, Stephen Thomas ${ }^{2}$, Paul Granato $^{2}$, Amit Sharma ${ }^{3}$, Ambika Eranki $^{2}$, and Tasaduq Fazili ${ }^{2}$ \\ ${ }^{1}$ SUNY Upstate Medical University, Internal Medicine, NY 13202, USA \\ ${ }^{2}$ Upstate Medical University, Division of Infectious Diseases, Syracuse, NY 13210, USA \\ ${ }^{3}$ Geisinger Health System, Scranton, PA 18503, USA
}

\begin{abstract}
A 46-year-old Caucasian female was diagnosed with invasive lobular carcinoma of the left breast. She underwent mastectomy and placement of a silicone breast implant as a single-stage procedure. Two weeks after surgery, she developed erythema and drainage to the postoperative site, necessitating removal of the breast implant. Operative cultures grew Mycobacterium goodii. She was successfully treated with a three month course of moxifloxacin and doxycyline. M. goodii should be in the differential of postoperative wound infections, including breast implants.
\end{abstract}

\section{Introduction}

Mycobacterium goodii is a non-tuberculous mycobacterium belonging to the Mycobacterium smegmatis class. Several reports of $M$. goodii infection have been documented but breast implant infection has not been previously reported. We report the first case of breast implant infection due to $M$. goodii and review the literature.

\section{Case presentation}

A 46-year-old Caucasian female with past medical history significant for Factor V Leiden mutation (a genetic mutation of a blood clotting factor that increases the risk of blood clots) and hyperlipidemia, was diagnosed with Grade 2 invasive lobular carcinoma of the left breast. She underwent mastectomy and placement of a silicone breast implant as a single-stage procedure. Her post-operative course was eventful for increased redness and drainage at the site of the breast implant, starting two weeks after surgery. The patient was treated with cephalexin and clindamycin but did not show any significant improvement. She was taken to the operating room for irrigation and debridement, with retention of the implant. "Murky" fluid was noted at the operative site which was evacuated. In view of failure to improve clinically over the next week, she was taken back to the operating room for additional surgical debridement and removal of the breast implant. Samples from the debrided material from both surgeries were sent to the microbiology laboratory for bacteriologic culture. Direct Gram stain smear showed the presence of "many white blood cells but no bacteria seen". The specimens were inoculated onto $5 \%$ sheep blood (BAP) and chocolate agar plates along with a thioglycolate broth which were incubated in a $5 \% \mathrm{CO}_{2}$ atmosphere at $35^{\circ} \mathrm{C}$. Culture plates were examined daily for up to 5 days. After 4 days of incubation, small, pinpoint growth was detected on the BAP. Gram stain of the colonial growth showed the presence of beaded, grampositive bacilli suggestive of an atypical mycobacterium in morphologic appearance. A Kinyoun stain was performed which confirmed that the organism was an acid-fast bacillus (AFB).

The isolate was sent to a reference laboratory (ARUP Laboratories, Salt Lake City, UT) where it was identified as M. goodii using MALDI-
ToF technology (Bruker Daltonics, Waltam, MA). Quantitative antibiotic susceptibility testing was also performed to determine the isolate's minimum inhibitory concentration (MIC) to various drugs. The isolate was resistant to clarithromycin, MIC $>32 \mathrm{ug} / \mathrm{ml}$ but susceptible to amikacin, $<1 \mathrm{ug} / \mathrm{ml}$; ciprofloxacin, $1 \mathrm{ug} / \mathrm{ml}$; doxycycline, $0.12 \mathrm{ug} / \mathrm{ml}$; imipenem, $<2 \mathrm{ug} / \mathrm{ml}$; linezolid, $2 \mathrm{ug} / \mathrm{ml}$; minocycline, $<1 \mathrm{ug} /$ $\mathrm{ml}$; moxifloxacin, $<0.25 \mathrm{ug} / \mathrm{ml}$; and, trimethoprim/sulfamethoxazole, $<0.25 / 4.8 \mathrm{ug} / \mathrm{ml}$. The patient's antibiotic regimen was modified from empiric linezolid and azithromycin, started by a different provider, to oral doxycycline and moxifloxacin. The regimen was continued for three months. She did well clinically, made an uneventful recovery, and subsequently had a new implant placed, three months after finishing the course of antibiotics. The patient continues to do well with no recurrence of infection, six months later.

\section{Discussion}

M. goodii are gram-positive, non-motile, rapid growing acid fast bacilli. The M. smegmatis group was first described and isolated by Lustgarten in 1885 , and was so named because of its presence in the smegma of normal penile secretions. M. smegmatis was initially thought to be a non-pathogen. However, in 1988, Wallace, et al. [1] reported several cases of $M$. smegmatis infection, principally involving the skin and soft tissue. In 1999, Brown et al. [2] studied 71 clinical isolates that had been previously identified as M. smegmatis. In addition to performing routine biochemical testing and studying physiologic growth characteristics and antimicrobial susceptibility patterns, the authors used several newly-available molecular techniques to determine whether these isolates were, in fact, different species. These

Correspondence to: Aakriti Pandita, SUNY Upstate Medical University, Internal Medicine, 750 E Adams st, Syracuse, NY 13202, USA, Tel: 646634 1562; E-mail: pandita.aakriti@gmail.com

Key words: mycobacteria, breast implant infection, antibiotics

Received: March 19, 2017; Accepted: April 17, 2017; Published: April 20, 2017 
new technologies included high pressure liquid chromatography to study mycolic acid ester elution patterns, polymerase chain reaction restriction analysis of the $65 \mathrm{kDa}$ heat-shock protein gene, $16 \mathrm{~s}$ restriction fragment length polymorphism analysis, and DNA-DNA hybridization assays. Based on these studies, the authors concluded that the 71 isolates were actually three different species groups which they categorized as follows: $M$. smegmatis sensu stricto (group 1; 35 isolates), M. goodii (group 2; 28 isolates), and M. wolinskyi (group 3; 8 isolates).

Table 1.Patient and management details of patients with M. goodiiinfection.

\begin{tabular}{|c|c|c|c|c|c|c|c|}
\hline Ref & No.ofpts & Age & Sex & Source & Diagnosis & Antimicrobial therapy & Duration of therapy (mo) \\
\hline \multirow[t]{5}{*}{3} & 1 & 76 & $\mathrm{~F}$ & Blood & Prosthetic valve endocarditis & Meropenem, gent, cipro & 4.25 \\
\hline & & & & & & x 2 weeks, followed by & \\
\hline & & & & & & amp, gent, cipro $\mathrm{x} 2$ weeks & \\
\hline & & & & & & tigecycline, cipro x 2 weeks & \\
\hline & & & & & & doxy, cipro x 11 weeks & \\
\hline 4 & 1 & 15 & $\mathrm{~F}$ & Bronch & Pulmonary infection & Cipro, doxy x 12 months & 12 \\
\hline 5 & 1 & 44 & M & Prosthetic knee & Prosthetic joint infection & Minocycline, cipro x 6 months & 6 \\
\hline \multirow[t]{2}{*}{6} & 1 & 23 & M & Pacemaker pocket & Pacemaker surgical site & Ofloxacin, doxy x 4 months & 4 \\
\hline & & & & & Infection & & \\
\hline \multirow[t]{2}{*}{7} & 1 & 85 & M & Pacemaker pocket & Pacemaker surgical site & Trim/sulfa $\times 8$ weeks & 2 \\
\hline & & & & & Infection & & \\
\hline 8 & 1 & 66 & M & Pleural fluid & Pneumonia/empyema & Unavailable & Unavailable \\
\hline 9 & 1 & 67 & M & Vitreous & Postcataractendophthalmitis & Intravitrealamikacin (twice) & No systemic therapy \\
\hline \multirow[t]{4}{*}{10} & 3 & & & & & Unavailable & Unavailable \\
\hline & & 64 & M & Prosthetic hip & Prosthetic hip infection & & \\
\hline & & 64 & M & Hernia patch & Inguinal hernia patch infection & & \\
\hline & & 75 & $\mathrm{~F}$ & Prosthetic knee & Prosthetic knee infection & & \\
\hline 11 & 1 & 65 & M & Hernia mesh & Inguinal hernia mesh infection & Trim/sulfa x 1 month & 1 \\
\hline 12 & 1 & 60 & M & Olecranon bursa & Olecranon bursitis & Cipro, doxy x 2.5 months & 2.5 \\
\hline \multirow[t]{29}{*}{2} & 28 & & & & & Unavailable & Unavailable \\
\hline & & 22 & M & Calcaneus & Osteomyelitis following trauma & & \\
\hline & & 20 & $\mathrm{~F}$ & Femur & Osteomyelitis from open fracture & & \\
\hline & & 73 & M & Toe & $\begin{array}{l}\text { Osteomyelitis from stepping } \\
\text { on nail }\end{array}$ & & \\
\hline & & 21 & M & Tibia & $\begin{array}{l}\text { Osteomyelitis from puncture } \\
\text { wound }\end{array}$ & & \\
\hline & & 55 & $\mathrm{~F}$ & Elbow & Osteomyelitis from open fracture & & \\
\hline & & 18 & M & Leg & Infected wound, ? Osteomyelitis & & \\
\hline & & 30 & $\mathrm{~F}$ & Tibia & Osteomyelitis following fracture & & \\
\hline & & NA & $\mathrm{F}$ & Femur & Osteomyelitis (post-surgical) & & \\
\hline & & 26 & F & Thigh, femur & Osteomyelitis following trauma & & \\
\hline & & 12 & M & Cheek & Cellulitis & & \\
\hline & & 16 & M & Femur & Osteomyelitis from open fracture & & \\
\hline & & 13 & M & Thigh & Cellulitis/chronic draining sinus & & \\
\hline & & 64 & M & Blood & Intravenous catheter sepsis & & \\
\hline & & 62 & M & Sternum & $\begin{array}{l}\text { Osteomyelitis following cardiac } \\
\text { bypass }\end{array}$ & & \\
\hline & & 26 & F & Breast & \multicolumn{2}{|c|}{ Infection following breast reduction surgery } & \\
\hline & & 20 & $\mathrm{~F}$ & Pacemaker & Infected pacemaker site & & \\
\hline & & 91 & $\mathrm{~F}$ & Pacemaker & Infected pacemaker site & & \\
\hline & & 60 & M & Sternum & Wound infection, ?osteomyelitis & & \\
\hline & & & & Pleural fluid, lung biopsy & Lipoid pneumonia & & \\
\hline & & 76 & $\mathrm{M}$ & Lung mass & Chronic granulomatous disease & & \\
\hline & & 56 & M & Bronchial wash & Necrotizing pneumonia & & \\
\hline & & 34 & $\mathrm{~F}$ & Lung biopsy & Lipoid pneumonia & & \\
\hline & & 18 & M & Lung biopsy & Lipoid pneumonia & & \\
\hline & & 53 & M & Sputum & Achalasia/pneumonia & & \\
\hline & & 90 & M & CSF & NA & & \\
\hline & & 40 & M & Thigh & NA & & \\
\hline & & 69 & M & Knee aspirate & NA & & \\
\hline & & 18 & $\mathrm{~F}$ & Arm & NA & & \\
\hline
\end{tabular}

Using the PubMed search, we reviewed all cases of $M$. goodii infection reported in the English language to date. Forty cases were documented, including the 28 cases that were described in the initial review by Brown et al. [2]. Since that review, an additional 12 cases have been reported. Our case thus documents the forty-first case of $M$. goodii infection reported in the English literature, and the first case involving an infected breast implant.

Table 1 summarizes some details regarding the infected patients. The average age of the patients was 47 years. Male-to-female ratio was 
2:1. Osteomyelitis was the most frequent diagnosis, with ten definite and two probable cases. All of these cases were reported by Brown et al. [2]. There were seven cases of pulmonary infection, including three cases of lipoid pneumonia. Two patients with pneumonia had underlying achalasia as a possible predisposing condition. Pacemaker surgical site infections were the next most frequent, with four cases. Three patients had a prosthetic joint infection, two of which were part of a three-patient nosocomial outbreak. Two patients each had a hernia patch/mesh infection, an infected wound (leg, sternum), and cellulitis (face, thigh). One patient each had a prosthetic valve endocarditis, olecranon bursitis, breast reduction surgical site infection, intravenous catheter sepsis, and post-cataract endophthalmitis.

The ecologic niche for $M$. goodii is incompletely defined. The source of infection likely is environmental, although this has not been definitively proven $[3,4]$.

Antibiotic susceptibility results for $M$. goodii are somewhat limited. The initial review by Brown and colleagues [2] showed that their isolates were resistant to clarithromycin, cefoxitin, and cefmetazole; were variably susceptible to tobramycin; and, were susceptible to amikacin, doxycycline, imipenem, ciprofloxacin, and sulfamethoxazole. Subsequent studies have reported somewhat similar susceptibility results, although these studies report only a limited number of antibiotics [4-12]. A recent study reported very low MICs to moxifloxacin $(0.032 \mathrm{ugm} / \mathrm{ml})$ and tigecycline $(0.016 \mathrm{ugm} / \mathrm{ml})$ [5].

Treatment details were available for only eight of the forty patients in our review. Treatment duration ranged from 1 to 12 months. Relatively short courses of therapy ( 1 to 4 months) were used for superficial surgical site and wound infections while longer therapeutic courses (6 to 12 months) were used for deeper infections, such as prosthetic joints and pneumonia. The most commonly reported antibiotic combination used for treatment was a quinolone (ciprofloxacin or ofloxacin) along with a tetracycline (doxycycline or minocycline), used predominantly for deeper infections. Trimethoprim/sulfamethoxazole was the next most commonly used drug but it was used as monotherapy for more superficial infections.

In keeping with our findings, previous reports support a twodrug antimicrobial regimen for 3 to 4 months for skin and soft tissue infections, and at least 6 months for bone and joint infections. In addition to antimicrobial therapy, surgical debridement and removal of any prosthetic devices or foreign material, is likely a requirement for achieving clinical and microbiologic cure. We treated our patient with a combination of moxifloxacin and doxycycline for a three-month course of therapy, along with removal of the breast implant, with a favorable outcome.

\section{Conclusions}

M. goodii is a rapidly growing mycobacterium that can cause a variety of infections, most commonly post-operative and post-traumatic wound infections, osteomyelitis, and prosthetic joint infections. We report the first case of breast implant infection due to $M$. goodii. Dual antibiotic therapy with a quinolone and tetracycline, achieved complete cure in our case, and supports the use of combination therapy. For skin/ soft tissue and wound infections, a 3 to 4 month course of antibiotics appears reasonable, while for osteomyelitis and septic arthritis, at least 6 months of therapy is recommended. More widespread use of improved identification techniques, such as MALDI-ToF and gene sequencing, will likely identify $M$. goodii as an increasingly prevalent pathogen.

\section{Conflict of interest}

\section{None}

\section{References}

1. Wallace RJ Jr, Nash DR, Tsukamura M, Blacklock ZM, Silcox VA (1988) Human disease due to Mycobacterium smegmatis. J Infect Dis 158: 52-59. [Crossref]

2. Brown BA, Springer B, Steingrube VA, Wilson RW, Pfyffer GE, et al. (1999) Mycobacterium wolinskyi sp. nov. and Mycobacterium goodii sp. nov., two new rapidly growing species related to Mycobacterium smegmatis and associated with human wound infections: a cooperative study from the International Working Group on Mycobacterial Taxonomy. Int J Syst Bacteriol 4: 1493-1511. [Crossref]

3. Marchandin H, Battistella P, Calvet B, Darbas H, Frapier JM, et al. (2009) Pacemaker surgical site infection caused by Mycobacterium goodii. J Med Microbiol 58: 517-520. [Crossref]

4. Ferguson DD, Gershman K, Jensen B, Arduino MJ, Yakrus MA, et al. (2004) Mycobacterium goodii Infections Associated with Surgical Implants at Colorado Hospital. Emer Infect Dis 10: 1868-1871. [Crossref]

5. Jönsson G, Rydberg J, Sturegård E, Christensson B (2012) A Case of Mycobacterium Goodii Prosthetic Valve Endocarditis in a non-Immunocompromised patient: use of 16S RDNA Analysis for Rapid Diagnosis. BMC Infect Dis 12: 301. [Crossref]

6. Martinez-Gonzalez D, Franco J, Navarro-Ortega D, Munoz C, Marti-Obiol R, BarrasSalvador R. Achalasia and Mycobacterium goodii pulmonary infection. Pediatr Infect Dis J 30: 447-448. [Crossref]

7. Ahmad S, Khakoo RA (2010) Left knee prosthesis-related Mycobacterium goodi infection. Int J Infect Dis 14: e1115-1116. [Crossref]

8. Chrissoheris MP, Kadakia H, Marieb M, Libertin C (2008) Pacemaker pocket infection due to Mycobacterium goodii: case report and review of the literature. Conn Med 72 75-77. [Crossref]

9. Buijtels PC, Petit PL, Verbrugh HA, van Belkum A, van Soolingen D (2005) Isolation of nontuberculous mycobacteria in Zambia: eight case reports. $J$ Clin Microbiol 43 . 6020-6026. [Crossref]

10. Spencer TS, Teske MP, Bernstein PS (2005) Postcataract endophthalmitis caused by Mycobacterium goodii. J Catartact Refract Surg 31: 1252-1253. [Crossref]

11. Sohail MR, Smilack JD (2004) Hernia repair mesh-associated Mycobacterium goodii infection. J Clin Microbiol 42: 2858-2860. [Crossref]

12. Friedman ND, Sexton DJ (2001) Bursitis due to Mycobacterium goodii, a recently described, rapidly growing mycobacterium. J Clin Microbiol 39: 404-405. [Crossref]

Copyright: (C2017 Pandita A. This is an open-access article distributed under the terms of the Creative Commons Attribution License, which permits unrestricted use, distribution, and reproduction in any medium, provided the original author and source are credited. 